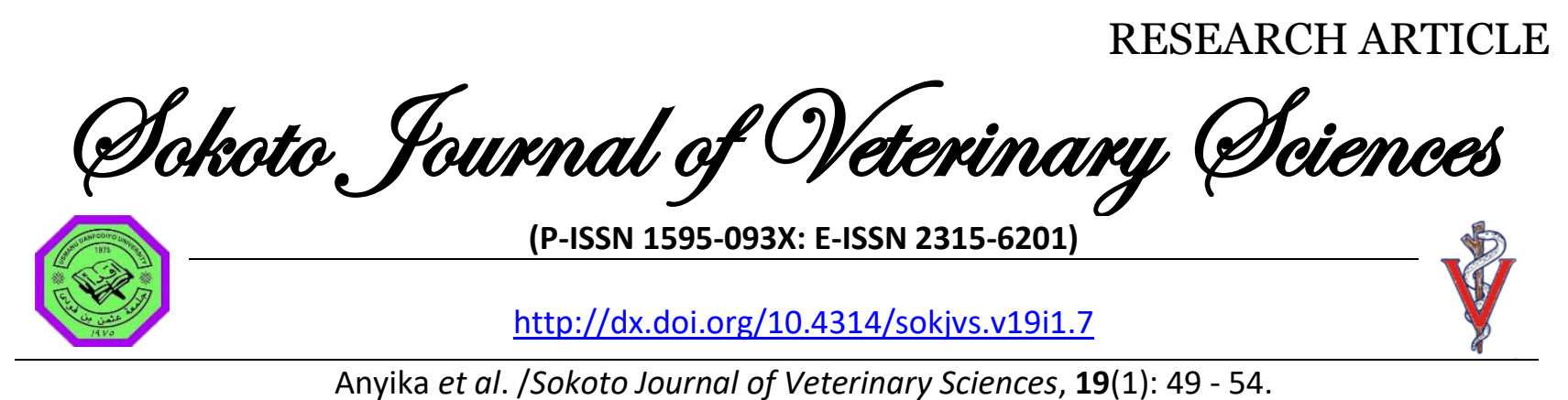

\title{
Seroprevalence of contagious bovine pleuropneumonia in three selected south-eastern states of Nigeria
}

\author{
KC Anyika ${ }^{1 *}$, SO Okaiyeto ${ }^{2}$, AK Sackey ${ }^{3}$, CN Kwanashie ${ }^{4}$ \& LT Ikpa ${ }^{5}$ \\ 1. \\ Livestock Investigation Division, National Veterinary Research Institute, Vom, Nigeria \\ 2. Veterinary Teaching Hospital, Ahmadu Bello University, Zaria, Nigeria \\ 3. Department of Veterinary Medicine, Ahmadu Bello University, Zaria, Nigeria \\ 4. Department of Veterinary Microbiology, Ahmadu Bello University, Zaria, Nigeria \\ 5. Mycoplasma Laboratory, National Veterinary Research Institute, Vom, Nigeria
}

*Correspondence: Tel.: + 2347030564505; E-mail: chinetoanyika@gmail.com

\begin{abstract}
Copyright: (C) 2021
Anyika et al. This is an open-access article published under the terms of the Creative Commons Attribution License which permits unrestricted use, distribution, and reproduction in any medium, provided the original author and source are credited.
\end{abstract}

Publication History: Received: 22-11-2020

Revised: 01-01-2021

Accepted: 15-01-2021

\begin{abstract}
Contagious bovine pleuropneumonia is a trans-boundary animal disease caused by Mycoplasma mycoides subsp. mycoides. This study was designed to determine the seroprevalence of contagious bovine pleuropneumonia (CBPP) in three selected south eastern states (Anambra, Enugu and Imo) of Nigeria using competitive enzyme-linked immunosorbent assay (c-ELISA). A total of 438 bovine sera samples were collected randomly for four months (December 2019 to March 2020) and screened for antibodies to Mycoplasma mycoides subsp. mycoides (Mmm) using IDEXX CBPP antibody ELISA kit (CIRAD, France). Results showed an overall prevalence of $59.4 \%$ for the three states screened. Antibodies to $\mathrm{Mmm}$ were detected in all the three states. Enugu state had the highest prevalence (64.3\%) followed by Imo state $(63 \%)$ and Anambra state $(50.7 \%)$. Female animals had higher prevalence of CBPP than male. However, it was not statistically significant $(P>0.05)$. This study confirms the presence of CBPP in south eastern Nigeria, and could be used as a base line data for future studies in this region. It is recommended that active surveillance and vaccination protocol should be undertaken in the region for the control and prevention of this disease.
\end{abstract}

Keywords: c-ELISA, Contagious bovine pleuropneumonia, Mycoplasma, Nigeria, Seroprevalence

\section{Introduction}

Contagious Bovine Pleuropneumonia (CBPP) is a highly contagious disease of cattle caused by Mycoplasma mycoides subsp. mycoides ( $\mathrm{Mmm}$ ) (Egwu et al., 1996; Campbell, 2015). Based on its transmissibility and economic impacts, CBPP is recognized as a priority trans-boundary disease (TAD) and has thus been categorized as the only bacterial disease in the OIE list A diseases (Litamoi et al., 2005). CBPP is characterized by a relatively long incubation period and highly inconsistent clinical course (Litamoi et al., 2005). Clinical signs of the disease include anorexia, fever, dyspnea, cough and nasal discharges (Campbell, 2015). In adult, most infections are limited to the respiratory tract, while 
in calves the disease is usually characterized by arthritis (Campbell, 2015). The disease is considered to be the most economically important cattle disease in Africa causing greater losses in cattle than any other disease (OIE, 2003). The annual economic loss due to CBPP in the northern states of Nigeria was then estimated at NGN 498 million (Fayomi \& Aliyu, 1997). A five-year retrospective study at Mubi, Adamawa state by Halle et al. (1998) reported that 238 infected cattle lungs were condemned due to CBPP out of 43,810 cattle slaughtered $(0.54 \%)$ and the worth of organs condemned was estimated at NGN 28,580.

The establishment of the true prevalence rates of CBPP in infected countries is an important prerequisite to mounting a successful control programme of the disease (FAO, 2004). Serodiagnosis plays an important role in the survey and control programs of CBPP (Le Goff \& Thiaucourt, 1998). There are two OIE approved serological tests for the diagnosis of CBPP, the complement fixation test (CFT) and the competitive ELISA.

CBPP is an economically important disease condition; this emphasizes the need for an accurate data on the prevalence of the infection, if prompt and effective control measures are to be instituted. Presently, in Nigeria, the extent and pattern of CBPP in south east Nigeria is largely unknown, as many studies have centered within the northern region of the country (Nwanta \& Umoh, 1992; Nwankpa, 2008; Okaiyeto et al., 2011; Jasini et al., 2016). The south east region of Nigeria is estimated to have a cattle population of 4.5 million, there is an apparent successful settlement of pastoralists within the southern region of Nigeria in the past two decades

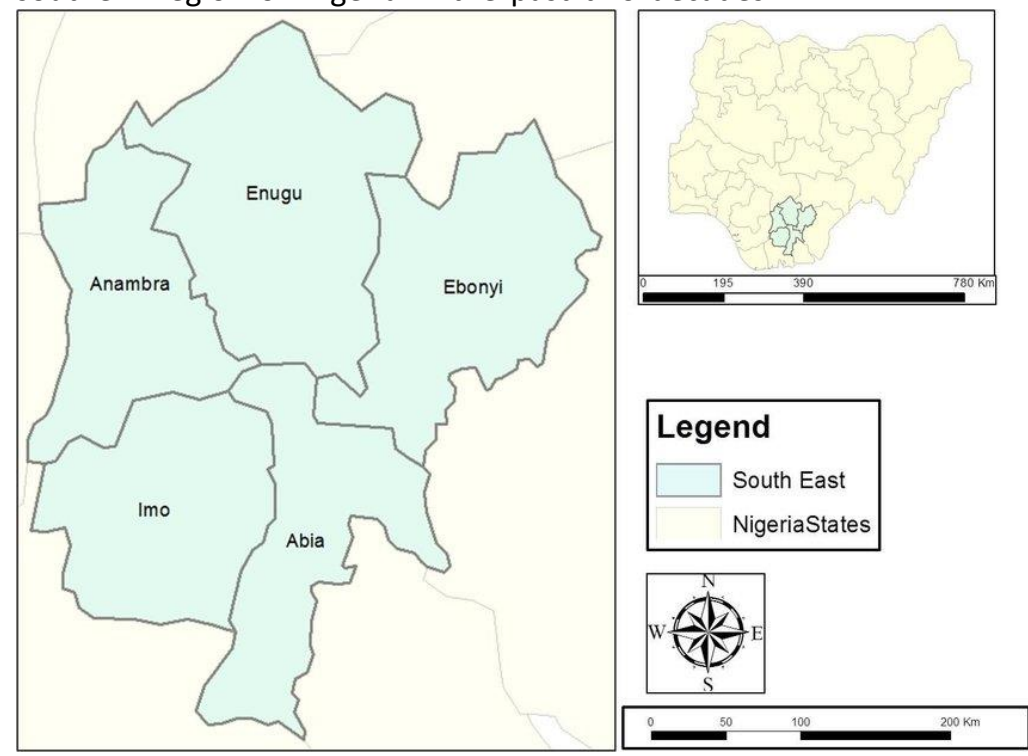

Figure 1: Map of Nigeria showing the south-eastern states with thousands of zebu cattle (Blench, 1994). Furthermore, data generated from this research will serve as baseline data for future studies within these States.

\section{Materials and Methods}

Study area

This study was conducted in three selected south eastern states of Nigeria (Anambra, Enugu and Imo states). South east Nigeria is one of the six geopolitical zones in the country. The region consists of Anambra, Enugu, Imo, Ebonyi and Abia states (Figure 1). Anambra state lies between latitude $5^{\circ}$ $32^{\prime}$ and $6^{\circ} 45^{\prime} \mathrm{N}$ and longitude $6^{\circ} 43^{\prime}$ and $7^{\circ} 22^{\prime} \mathrm{E}$; Enugu state lies between latitude $5^{\circ} 27^{\prime}$ and $6^{\circ} 33^{\prime} \mathrm{N}$ and longitude $6^{\circ} 28^{\prime}$ and $7^{\circ} 32^{\prime} \mathrm{E}$ and Imo state is located between latitude $4^{\circ} 45^{\prime}$ and $7^{\circ}$ and $15^{\prime} \mathrm{N}$ and longitude $6^{\circ} 50^{\prime}$ and $7^{\circ} 25^{\prime} \mathrm{E}$. The south eastern region of Nigeria has an estimated cattle population of 4.5 million from the total 16.3 million estimated cattle population in Nigeria (Ikhatua, 2011).

\section{Sample collection}

Blood samples were collected randomly from cattle in Fulani sedentary settlements within the three selected south eastern states. Furthermore, blood samples were only collected from cattle that were not vaccinated against CBPP in the past 6 months and apparently sick animals. Sex of animals sampled was also documented.

Blood samples $(5 \mathrm{ml})$ were aseptically collected through the jugular vein of each animal using sterile $18 \mathrm{G}$ needle and $10 \mathrm{ml}$ syringe. The blood samples were allowed to stand in a slanting position for 5 about hours to allow for separation of the serum

from the cellular components of the blood. The serum was then harvested into labeled sample bottles and packed on ice for onward transport to the Mycoplasma laboratory of the National Veterinary Research Institute Vom for serological examination.

\section{Serological analysis}

The serological analysis was performed using IDEXX CBPP antibody Test Kit (P05410/10, CIRAD, France) according to manufacturer's instruction. Briefly, the serum test samples were premixed with a specific monoclonal 
antibody Mab 117/5 in a separate plate called the 'pre-plate' and the content of the pre-plate was then transferred into the pre- coated micro-plate lysed with Mycoplasma mycoides subsp. mycoides antigen and incubated for 1 hour at $37^{\circ} \mathrm{C}$ under gentle agitation. The unbound materials were washed twice with phosphate-buffered saline $(300 \mu l)$ and an anti-mouse conjugate concentrate $(100 \mu \mathrm{l})$ was then added to each well. This was again incubated for 30 minutes at $37^{\circ} \mathrm{C}$ under gentle agitation, avoiding the desiccation of the plates. After incubation, the unbound materials were again washed three times with phosphate-buffered saline $(300 \mu \mathrm{l})$. Subsequently, $100 \mu \mathrm{l}$ of an enzyme substrate (TMB) was then added to each well and incubated for 20 minutes at $37^{\circ} \mathrm{C}$. Finally, the reaction was stopped by adding $100 \mu \mathrm{l}$ of a stop solution (sulphuric acid) into each well. The optical densities of the reactions were then read at 450nm using Multiskan EX (Labsystems). Samples were considered negative if the percentage inhibition was below $50 \%$ and positive above $50 \%$.

\section{Data analysis}

The data obtained are presented in tables. Chisquare test using SPSS Version 20 for windows was used to determine any significant difference in the prevalence rate of the disease based on sex of cattle. Values of $P \leq 0.05$ were considered significant at $95 \%$ confidence Interval. Prevalence rate was calculated using the formula:

$$
\text { Prevalence }=\frac{\text { Positive samples }}{\text { Total samples analyzed }} \times 100
$$

\section{Results}

The result for the sero-prevalence of CBPP in the three south east states using competitive ELISA is presented in Table 1 . Out of the total of 438 sera samples collected, 260 were positive for CBPP, giving an overall prevalence of $59.4 \%$ (Table 1 ). Out of the 146 sera samples collected from each state, 74 (50.7\%) were positive for CBPP antibodies in Anambra State, while 92 (63\%) were positive in Imo state and 94(64.3\%) were positive for CBPP antibodies in Enugu state (Table 1).

Based on sex, 19 (19\%) bulls tested for CBPP antibody in the three selected south east states were positive for CBPP, while 241 (71\%) cows out of 338 sampled were also positive (Table 2 ) however, it was not statistically significant $(P>0.05)$.

\section{Discussion}

In this study, the overall seroprevalence of CBPP using C-ELISA in the study area was $59.4 \%$. This high prevalence recorded in the study area may be attributed to several factors such as; breakdown in veterinary services within this region. This has adversely affected the quality of veterinary services within this region and as such most of the herdsmen/ cattle owners resort to self-help in the management of the disease. This is similar to study by Ankeli et al. (2017). Similarly, indiscriminate use of antibiotics by herdsmen/pastoralists for the treatment of CBPP as reported by Egwu et al. (2012) could also account for the high prevalence recorded in the study.

Indiscriminate use of antibiotics could lead to the establishment of chronic carriers of the disease, thereby facilitating the spread of the disease to susceptible animals within the herd. In Nigeria, a live with the disease attitude has prevailed over the past five years; farmers rarely report cases of CBPP but resort to treatment with antibiotics like any other bacteria disease (Chima et al., 2001). Furthermore, lack of access to quality and well preserved CBPP vaccines by herdsmen in the study area could also

Table 1: Sero-prevalence of CBPP in the three selected south east states, Nigeria

\begin{tabular}{lll}
\hline States & Number sampled & Number Positive by c-ELISA (\%) \\
\hline Anambra & 146 & $74(50.7)$ \\
Enugu & 146 & $94(64.3)$ \\
Imo & 146 & $92(63)$ \\
Total & 438 & $260(59.4)$ \\
\hline
\end{tabular}

Table 2: Sero-prevalence of CBPP based on sex of cattle in the three selected south east states, Nigeria

\begin{tabular}{llllll}
\hline State & \multicolumn{2}{c}{ Sex } & P-value \\
& \cline { 2 - 5 } & Sampled & Positive (\%) & Sampled & Positive (\%) \\
\hline Anambra & 32 & $6(18.7)$ & 114 & $68(59.6)$ \\
Enugu & 40 & $6(15)$ & 106 & $88(83)$ \\
Imo & 28 & $7(25)$ & 118 & $85(72)$ & \\
Total & 100 & $19(19)$ & 338 & $241(71)$ & 0.063 \\
\hline
\end{tabular}


account for the high prevalence of CBPP recorded in this study, as most of them purchase CBPP vaccines from the open markets rather than NVRI outstations within the region. This is similar to report by Billy (2014), who also reported high patronage of CBPP vaccine from open market by pastoralists. Similarly, improper vaccination practices undertaken by the herdsmen could also attribute to the high seroprevalence of CBPP recorded in this study, as some of the herdsmen engage in the act of mixing different vaccines types within the same bottle before vaccinating their cattle (personal experience). This practice could affect the potency of the vaccine due to under dosage of the vaccine and wrong route of vaccination. The high seroprevalence of CBPP recorded in the study area, could also be because apparently healthy animals not showing clinical signs of the disease were sampled. Consequently, some infected animals within the incubatory stage of the disease and also those recovered from CBPP (lungers) would have been sampled. The high prevalence of CBPP recorded in this region may indicate the endemicity of the disease in south east Nigeria. This is in agreement with the annual report by OIE (2009) which stated that CBPP is gradually spreading across Nigerian states from the northern Region to other regions because of constant migration of cattle herders. It is noteworthy to state that this is the first time such study was undertaken within the south eastern region of Nigeria using this method. Most of the cases recorded in this study are likely due to natural infection as vaccination history was taken before sample collection. Moreso, this technique is capable of detecting field infections even in areas where vaccination is practiced as antibodies produced when T1/44 vaccine is administered to animals do not persist for more than 3 months (Le Goff \& Thiaucourt, 1998).

The findings in this study are similar to works done by Olorunshola et al. (2020), who recorded a high prevalence rate of $56.2 \%$ in the Middle-Belt region of Nigeria. Nwankpa (2008), also reported high prevalence of CBPP in some northern states of Nigeria such as; Bauchi state with $32.4 \%$, Gombe state $50.5 \%$ and Taraba State with 40\% CBPP seroprevalence rate. Similarly, Danbirni et al. (2010) reported a high CBPP seroprevalence of $47 \%$ in Kaduna State. This may be attributed to the endemicity of CBPP within the northern region of country where most of the cattle population is located (Egwu et al., 1996; Nwankpa, 2008). However, this finding is in contrast with studies by Olabode et al. (2013) who reported a lower CBPP prevalence of $10.65 \%$ in Kwara State and Jasini et al.
(2015) who also reported CBPP prevalence rate of $0.63 \%$ in Borno state. This lower prevalence recorded by these authors may be attributed to the absence of infection at the point of sampling and the smaller number of sera samples collected for screening of $\mathrm{Mmm}$ antibodies.

There was higher prevalence of CBPP observed in cows compared to bulls in this study. However, this was not significant. This finding is in accordance with studies by Nwankpa (2008) and Billy (2014) who both reported higher prevalence in cows than bulls. However, this is in contrast to works by Ankeli et al. (2017) who reported higher prevalence of CBPP in bulls than cows. This high prevalence could be because fewer bulls are usually kept in the herd than the cows. Most of the cattle owners fatten and sell most of the bulls in the herd so as to prevent competition during breeding. It could also be due to the fact the female animals stay longer within the herd, thereby increasing the chances of repeated exposure to the disease.

This study confirms the presence of contagious bovine pleuropneumonia in south east Nigeria and also indicates its endemicity in the region. Data from this study can be used for future studies and also in designing control measures for the control of the disease in this region.

It is therefore recommended that active disease surveillance and routine vaccination campaigns should be carried out within this region for the control and prevention of CBPP.

\section{Acknowledgments}

Special thanks to Director/Chief Executive NVRI, for the kind approval of some of the CBPP vaccines used as incentives in this study.

\section{Conflicts of Interest}

The authors declare no conflict of interest.

\section{References}

Ankeli PI, Raji MA, Kazeem HM, Tambuwal FM, Francis MI, Ikpa LT, Fagbamila IO, Luka PD \& Nwakpa ND (2017). Seroprevalence of contagious bovine pleuropneumonia in Plateau state, north-Central Nigeria. Bulletin of Animal Health and Production, 65(2):357-366.

Billy IL (2014). Seroprevalence and Awareness of Contagious Pleuropneumonia in cattle in three selected local government area of Kaduna state, Nigeria. MSc dissertation. Department of Veterinary Medicine, 
Ahmadu Bello University, Zaria, Nigeria. Pp 80-88.

Blench R (1994). The expansion and adaptation of Fulbe pastoralism to sub-humid and humid conditions in Nigeria. African studies Centre Leiden. Cahier d' Etudes Africaines, 34(133135): 197-212.

Campbell J (2015). Contagious Bovine Pleuropneumonia. In: The Merck's Veterinary Manual: (CM Kahn, S Line, SE Aiello, editors). Whitehouse Station, NJ: Merck and Co. www.merckvetmanual.com, retrieved 04-11-2015.

Chima JC, Lombin LH, Molokwu JH, Abiaye EA \& Majiyagbe KA (2001). Current situation of contagious bovine pleuropneumonia in Nigeria and the relevance of c-ELISA in the control of the disease. Proceedings of the Research coordination meeting of the FAO/IAEA coordinated research programme held in Nairobi, June 2001, Kenya.

Danbirni S, Okaiyeto SO, Pewan SB \& Kudi AC (2010). Concurrent infection of contagious bovine pleuropneumonia and bovine tuberculosis in Bunaji nomadic cows. Research Journal of Animal Science, 4(1): 23-25.

Egwu GO, Adamu M, Mshelia GD \& Bukar-kolo YM (2012). A sustainable laboratory approach for contagious bovine pleuropneumonia (CBPP) monitoring in Nigeria: Comparison between two serological tests in an endemic area complimented with post mortem lesions. African Journal of Microbiology Research, 6(30): 58905895.

Egwu GO, Nicholas RAJ, Ameh JA \& Bashiruddin JB (1996). Contagious bovine pleuropneumonia: An update. Veterinary Bulletin, 66(9): 875-888.

FAO (2004). Summary of Recommendations. Report of the 3rd Meeting of the FAOOIEAU/IBARIAEA Consultative Group on Contagious Bovine 134 Pleuropneumonia (CBPP), 12-14 November 2003, Rome, Italy. FAO, Rome. Pp 5-6.

Fayomi A \& Aliyu ID (1997). A retrospective study of the incidence of contagious bovine pleuropneumonia in Kano and environs. Proceedings of the Nigerian Veterinary Medical Association (NVMA) Annual Congress, Oshogbo. Pp 124-130.

Halle PD, Ajogi ID, Muzong B. \& Zafi MD (1998). A retrospective study on the incidence of contagious bovine pleuropneumonia (CBPP) in Mubi, Adamawa State, Nigeria. Tropical Veterinarian, 16(2): 143-147.

Ikhatua UJ (2011). Nigerian Institute of Animal Science (NIAS) Beef Cattle Production Report. Timestamp: 2011-02-18. http://repository.fuoye.edu.ng.

Jasini AM, James OO, Haruna MK, Nicholas ND, Andrea DP, Flavio S, Katiusia Z, Ann A, Massimo S \& Attilio P (2016). Molecular detection of Nigerian field isolates of Mycoplasma mycoides subsp. mycoides as causative agents of contagious bovine pleuropneumonia. International Journal of Veterinary Science and Medicine, 4(2): 4653.

Jasini AM, Livinus TI, Fati AL, Enenche FE \& Quagar JT (2015). Detection of antibodies to Mycoplasma mycoides subspecies mycoides in cattle using competitive enzyme-linked immunosorbent assay. International Journal of Current Microbiology and Applied Sciences, 4(8): 770-777.

Le Goff C \& Thiaucourt F (1998). A competitive ELISA for the specific diagnosis of contagious bovine pleuropneumonia (CBPP). Veterinary Microbiology, 60(2-4): 179-191.

Litamoi JK, Ayelet G \& Rweyemamu MM (2005). Evaluation of the xerovac process for the preparation of heat tolerant contagious bovine pleuropneumonia (CBPP) vaccine. Vaccine, 23(20): 2573-2579.

Nwankpa ND (2008). Serological and Molecular Studies of Mycoplasma mycoides mycoides Small Colony in Northern Nigeria. PhD Thesis. Department of Veterinary Pathology and Microbiology, University of Nigeria Nsukka.

Nwanta DR \& Umoh JU (1992). Epidemiology of contagious bovine pleuropneumonia (CBPP) in northern states of Nigeria: An update. Revue d'élevage et de médecine vétérinaire des pays tropicaux, 45(1): 17-20.

OIE (2003). Contagious Bovine Pleuropneumonia. Manual of Standards. Chapter 2:16.

OIE (2009). World Animal Health Information Database - Version: 1.4. World Animal Health Information Database. Paris, France: World Organisation for Animal Health. http://www.oie.int

Okaiyeto SO, Danbirni S, Allam L, Akam E, Pewan SB \& Kudi AC (2011). On farm diagnosis of contagious bovine pleuropneumonia in nomadic herds using latex agglutination test 
(LAT). Journal of Veterinary Medicine and Animal Health, 3(5):62-66.

Olabode HOK, Mailafia S \& Adah BMJ (2013). A serological evidence of contagious bovine pleuropneumonia antibodies in trade cattle (Bos Indicus) sold in Kwara State-Nigeria. Online International Journal of Microbiology, 1: (1): 14-19.
Olorunshola ID, Dadou BO, Ajiboye B, Folaranmi EB, Nicholas RAJ, Adegboye DS \& Peters AR (2020). Seroprevalence of contagious bovine pleuropneumonia and contagious caprine pleuropnemonia in the Middle-Belt of Nigeria. African Journal of Microbiology Research, 14(1): 25-31 